\title{
Vorwort: Zwischen Nation und Europa
}

Als ich im Winter 2008/2009 während eines Auslandssemesters in Polen über den Marktplatz in Kraków spazierte, sah ich eine kleine Ausstellung, die dort gerade aufgebaut worden war. Einfache Tafeln zeigten schwarz-weiße Fotografien von Menschen mit Bündeln und Koffern, auf Pferdewagen und in langen Trecks, dazu Tabellen, die Nummern versammelten, Listen mit Jahreszahlen und Texte, aus denen mir ein Wort ins Auge sprang: »wypędzenie«, Vertreibung. Ich trat näher und sah mir die Ausstellung an. Es ging um die Vertreibung der polnischen Bevölkerung nach dem Zweiten Weltkrieg aus den ehemaligen polnischen Ostgebieten und um deren Ansiedlung im Westen des neu entstandenen polnischen Staates. Die Bilder der Ausstellung berührten mich sofort, denn sie waren mir sehr vertraut. Bevor ich nach Polen ging, hatte ich ein Interviewprojekt mit meinem Großvater gemacht, der als Deutscher in Łódź geboren und aufgewachsen und dessen Familie 1945 nach Westen geflohen war. In den Wochen, als ich ihn täglich mit der Videokamera besuchte und befragte, hatte ich mich intensiv mit der Vertreibung der Deutschen aus Polen und den ehemaligen deutschen Gebieten im Osten beschäftigt. Die Schwarz-Weiß-Bilder von Flüchtlingstrecks, Pferdewagen, Koffern und Bündeln hatten mich begleitet. Doch standen sie für mich für deutsche Geschichte - von den Vertreibungen der polnischen Bevölkerung hatte ich bis dahin wenig gehört.

Hier auf dem Marktplatz wurde mir diese Geschichte nun mit den Bildern erzählt, die ich bisher aus einem anderen nationalen Kontext kannte. Ich begann mich zu fragen, weshalb ich so wenig über polnische Geschichte wusste, und warum die Geschichte von Flucht und Vertreibungen, aber auch allgemeine Geschichte, die ich in meiner Familie und im Schulunterricht gelernt hatte, vor allem als nationale Geschichte gerahmt worden war. Pol_innen war ganz ähnliches geschehen wie meinem Großvater, sie waren sogar oft in genau die Häuser gezogen, die deutsche Familien verlassen hatten. Doch Geschichte hatte ich bis zu diesem Tag vor allem als deutsche Geschichte gelernt. Gleichzeitig war ich, wie Tausende andere, als Erasmus-Studentin in Polen und hörte oft, wir seien in erster Linie nicht Deutsche, Pol_innen, Französ_innen, Spanier_innen und so weiter, sondern Europäer_innen. Nationale Grenzen sollten für uns keine Rolle mehr spielen, wir studierten, reisten, lebten und arbeiteten oft nicht in dem Land, in dem wir geboren worden und zur Schule gegangen waren. Beim Betrachten der Ausstellung kollidierten diese beiden Bilder vor meinem inneren Auge: nationale Vergangenheitsdeutungen und der Anspruch, Europäerin zu sein - die Nation und Europa. Wäre es möglich, fragte ich mich, Geschichte nicht als nationale Geschichte zu erzählen, sondern als eine, die den engen Rahmen der Nation übersteigt und so das Verbindende und Gemeinsame zwischen Menschen zeigt? 
Gibt es Bemühungen, Geschichte nicht als deutsche, polnische oder französische, sondern als gemeinsam europäische zu zeigen? Und was würden »Europa« und »europäisch « dann bedeuten? Aus dem Interesse für diese Fragen ist die vorliegende Studie entstanden. 